\title{
A Lesson from the Comparison of UK \& China on Key-Competencies
}

\section{Xie Bing}

School of Foreign Languages, Wuhan City Polytechnic, Wuhan, China

\section{Email address:}

28971052@qq.com

\section{To cite this article:}

Xie Bing. A Lesson from the Comparison of UK \& China on Key-Competencies. Science Innovation. Vol. 5, No. 5, 2017, pp. $272-276$. doi: $10.11648 /$ j.si.20170505.15

Received: April 26, 2017; Accepted: July 4, 2017; Published: July 19, 2017

\begin{abstract}
The key-competencies enhance the quality education while promoting the innovation and reform of primary education. The innovation and reform refers to the contents, methods and approaches, etc. With the research on key-competencies of UK and China, the comparison of the connotation of key-competencies, there is an analysis of the difference between their understandings. The research aims to learn a lesson from the key-competencies based on cultivation and subsequently sets out a clear view and direction for the similar research in China.
\end{abstract}

Keywords: Key- Competencies, UK \& China, Comparison, Lesson

\section{中英核心素养对比及启示研究}

谢冰

外语学院, 武汉城市职业学院, 武汉, 中国

邮箱

28971052@qq.com

摘要：核心素养在巩固前一阶段素质教育发展成果的同时，也推动着基础教育的改革创新。基础教育将面临培养内容、 方法及途径等方面的改革。在综述中英两国对核心素养研究现状的基础上, 本文对比两国核心素养内涵特征, 分析两 国核心素养内涵差异, 对比英国核心素养培养方面的经验, 为后续国内核心素养方面的培养研究做铺垫。

关键词: 核心素养, 中英, 对比, 启示

\section{1. 引言}

所谓核心素养，即是人在发展过程中所不可或缺的必 备品格及关键能力 $[1]$ 。以英国为代表的欧盟国家从 2001 年起就围绕着核心素养这一概念展开大规模的调查及研 究。基于“读、写、算”传统能力及针对 21 世纪人才的“新 基本技能”, 理事会负责核心素养研究专项工作小组提出 核心素养的最初设想, 并于2002年确定核心素养概念--核心素养代表了一系列知识、技能和态度的集合, 它们是
可迁移的、多功能的, 这些素养是每个人发展自我、融入 社会及胜任工作所必需的; 在完成义务教育时这些素养应 得以具备, 并为终身学习奠定基础[2]。核心素养的概念历 经先后三次调整, 并于 2006年形成正式版本。在过去的十 几年时间里, 包括英国在内的欧盟各国对核心素养有自己 的需求分析及定位, 并在课程改革及师资培训中予以实践 及评估, 取得了一些成绩。

作为经济、文化及教育等领域都处于发展阶段的中国, 近年来也开始意识到社会对人全面发展的需求, 基础教育 
的重心也由原来人的素质教育这一层面拓展到人的核心 素养培养。学者们纷纷开始探索适合本国学生的核心素养 概念及发展途径, 并在此基础之上结合课程改革, 最终形 成核心素养的评估之法。由北京师范大学等高校及基础教 育一线教师组成的近百名研究人员团队, 经过三年的理论 研究、实证调查及专家论证, 确定中国学生发展的核心素 养内容。最终由教育部基础教育二司委托专家予以审订, 并于2016年9月公布, 同时做出详细解释及说明。

本文基于中英两国核心素养概念各要素, 对比两国在 概念理解上的异同。在吸取英国先进的研究理念及成果经 验之上，希望找到适合我国基础教育的正面启示，从而促 进我国高校师范生必备品格及关键能力的提高。

\section{2. 国内外研究现状}

21 世纪初, 欧盟便展开了为实现欧盟教育与个人发展 而设定的工作研究。1997年经济合作与发展组织 ( Organization for Economic Co-operation and Development, 简称 OECD）启动的“素养的界定与遴选： 理念和概念基础”项目 (Definition and Selection of Competencies: Theoretical and Conceptual Foundations, 简 称 $\mathrm{DeSeCo}$ ）调查结果指出, 核心素养包含三大类: 互动 地使用工具、自主行动及在社会异质团体中互动。而这一 研究结果随后便成为英国等欧美国家学生核心素养内涵 的基础 [3]。

在长达 20 余年的核心素养研究中, 以英国为代表的欧 美发达国家已经取得了初步成效。荷兰学者沃格特在对比 世界上八大核心素养内容基础之上指出, 核心素养的内容 要求主要集中于协作、交往、信息通信技术素养、社会和 文化技能及公民素养这四类。核心素养的要求已经基本落 实到课堂教学中, 而且进展迅速。

目前, 英国对于核心素养的研究已经大多集中于评估 研究。就PISA评估体系排名一方来看, 英国的态度由最初 的冷漠, 转为积极向全世界各国学习教育方法等改变凸显 英国核心素养教育进入反思评估调整阶段 $[4,5]$ 。苏格兰 地区的Assessment if For Learning(AiFL)计划及英国国家 标准署（OFSTED）颁布的英国教育督导评估指标等分别 对学生个人、学校教育效能及学校领导与管理效能进行评 估, 其意味着英国进入核心素养教育的评估阶段。随着基 于合作性、跨学科性及情境性的课程改革的实施, 英国很 多中小学生初步具备自主学习能力。但核心素养的实施过 程中仍然有一些问题亟待解决。就课堂教学过程而言, 仍 然存在教师自我效能感低、教师课堂控制力强及学生自主 学习受限等问题[6]。就课堂教学效果而言, 也存在着学生 核心素养发展进程缓慢等问题[7]。

在我国，核心素养的发展大致历经了三个阶段。第一 阶段为重视基本技能及基础知识的双基阶段。[8]第二阶段 为以知识与方法目标、技能与过程目标及情感与价值观目 标为基础的三维目标阶段 [9]。第三阶段为核心素养为基础 的阶段。以2016年9月14日教育部基础教育二司确定中国 学生发展核心素养具体的三个方面颁布出台为限。核心素
养依据科学性、时代性和民族性, 以培养“全面发展的人” 为目标。

由于起步较晚, 我国针对核心素养的研究主要集中在 概念及内涵解读式的研究, 同时包括少部分课程改革及评 估等方面的研究。以裴新宁、刘新阳及张娜为代表的学者 对欧盟及经合组织提出的核心素养概念做了大量研究; 以 辛涛及姜宇为代表的学者对于核心素养与课程结合方向 上的探索较为深入---对于我国是走以美澳台为代表的核 心素养独立于体系之外并相互整合之路, 以芬兰为代表的 课程体系中设置学生核心素养并使二者紧密结合之路抑 或是走以日韩为代表的通过课程设置体现学生核心素养 却不单独规定核心素养之路有相对详尽的介绍。当然, 核 心素养发展之路在国内学者间没有形成统一的方案 [1]。虽 然国内的研究停留在概念及与课堂结合的推进上, 但北京、 上海等发达地区的基础教育已先行落实, 并取得了一些理 论成果及较为先进的课程教育模式。例如清华小学 “ $1+X$ ” 课程模式, 以“现象学”角度看核心素养, 教学成效较为显 著[10]。

教学方法是落实核心素养培养的主要手段之一[11]。 以核心素养培养目标的教学不仅为全国中小学教学的新 一轮改革拟定目标, 也将为高校师范专业教学改革奠定基 础。

\section{3. 中英核心素养对比}

针对核心素养的研究较多, 国内教育界对核心素养的 概念并不陌生。但随着核心素养的研究深入，借鉴有经验 国家核心素养发展的先进理念, 并进行对比研究显得十分 紧迫。

\section{1. 中英核心素养内涵}

由于地域、历史、经济及文化等因素的影响, 英国核 心素养教育理念与中国对比差异较大。英国学生的核心素 养分为能互动地使用工具、能在异质社会团体中互动及能 主支地行动这三部分, 其下包括有效的沟通、运用数学、 运用科技与信息等八个方面 $[3,12]$ 。

2002年3月由传统的读写及“新基本能力”组合而成的 最初版核心素养, 其内容是: 使用母语交流、使用外语交 流、算数与数科学和技能、信息技术、学会学习、人际与 公民素养、创业精神及一般文化常识。最终版本的核心素 养侧重于传统的语言、算术、文化及读写等技能。2003 年6月, 第二版核心素养将“传统的读算能力”划归到“算数 与读写（基本技能）”，将“外语的交流”泛化成“外语”，将 “人际公民素养”延展为“社会技能”。将人放之于社会, 且 “技能”、“素养”等关键词语开始出现在内容里。2003年11 月, 第三版的核心素养内容将 “算数与读写 (基本技能)” 改回“使用母语交流”, 重新强调母语的交际功能。“数学 素养”这一概念也更加明晰，而与此同时“一般文化常识” 也内化成“文化意识”，使之更能与个人的终身发展相匹配。 2006年12月最终版的核心素养与第三版变动不大, 贴合技 术发展的速度将“信息技术技能”改为“数字素养”, 将“人际 与公民素养”再度泛化为“社会与公民素养”, 从而强调人 
与社会的关系及核心素养存大的大环境。并在创业精神一 词前注入“主动意识”这一动因, “文化意识”也相应延伸为 “文化意识与表达”，强调终身学习的主动性及外延性。

国内核心素养的发展是建立在双基和素质教育发展 演变基础之上。1952年在教育界里出现以基础知识及基本 技能为培养要求的“双基”。2001年启动的新课程改革标志 着基础教育从“双基”走向“在过程中掌握方法, 获取知识, 形成能力, 培养情感态度价值观”的三维。由“双基”过渡 到“三维”是我国教育者在培养学生理念中取得的一个重 大突破---由原来纯粹的知识技能的培养, 开始关注到个性 化的差异培养。教育更加“个性化”, 不再仅仅只是针对知 识本身而言, 而更是针对个人。个人能力及情感态度价值 观得以养成的同时, 也为核心素养的提出奠定了理论及实 践基础。2016年9月由教育部基础教育司提出的核心素养, 是指为适应 21 世纪的社会变革, 人所应该具备的关键素养。 更简而言之，核心素养即“21世纪关键素养”[13]。较之于 传统的教育观既有传承的一面又有超越的一面。传承更多 的体现在“内涵上”，而超越更多的体现在“性质上”。中国 的核心素养分为文化基础、自主发展及社会参与三部分, 分别对应人文底蕴、科学精神及实践创新等六素养及包括 人文积淀、人文情怀及技术应用等十八要点。

\section{2. 英国核心素养的特征}

英国核心素养的建立基础是解决问题、提高效率，这 与英国工业发展的需求是相关联的。所以核心素养所培养 的人更倾向于社会和工作中的人, 英国核心素养的概念不 可避免的有以下几种特征。

\subsection{1. 社会性}

英国的核心素养是基于工作的素养（work-based competencies）。从人使用工具的能力, 到在社会团体中 互动的能力, 再到自主地解决问题的能力, 无一不是人在 社会交往中所应具备的素养。核心素养是教育与就业之间 的桥梁, 它以一种提高教育及劳动力市场的工具状态存在。 因为它包括处事中的大量指令及个人效益, 所以是衡量一 个人能否胜任某工作的标准, 是可以习得的[14]。在校学 习期间提前接受针对性的习得教育, 进入社会之后习得的 核心素养便能发挥作用, 对社会性的工作或交往形成有利 影响。

一方面, 随着社会生产力的变化, 人才市场注重人才 的灵活性、就业能力及知识技能等素养。另一方面, 创新 的环境之下教育的内涵因素也应伴随着知识创新及人力 的发展而同时发展。这也就意味着, 学生在校期间所学到 的不仅仅是知识, 也应该是能够适应社会变化而变化的学 习能力。

\subsection{2. 实践性}

从使用语言、沟通及信息技术，到社会团体中的人际 交往与合作, 再到主动的解决问题、处理变化及学习提高 等, 都是能动的实践过程。核心素养最初被认为是完成一 项任务、提高效率及产值以及管理功效的“最好方式”[14]。 在为完成某项任务而采用“语言沟通-现代技术-团队合作-
方式解决-提高自身”的过程, 可以视之为核心素养的养成 过程。

基于工作的英国核心素养内涵本身就是建立在雇员 的工作属性及完成某项工作的个人能力之上, 它是衡量雇 员工作的标准。既然是衡量工作质量的标准, 必然需要在 工作的环境中才能施展开来, 所以实践性成为英国核心素 养的第二个特征。

\subsection{3. 个人性}

相对于社会性而言, 传统的观念认为核心素养与个人 的特性相关联。在这种思想指导之下, 英国学者有两种截 然不同的观点: 第一, 核心素养是可习得的。即核心素养 的可训练维度可以被利用而习得。而且工作环境下的学习 潜能也对个人核心素养能力的发展起推动作用。第二, 核 心素养是不可习得的。因为像情感、态度以及认知等内容 都不是被习得, 而是被发展所得。与此同时, 有一个观念 表明核心素养与能力不相关, 只是雇员在特定场合之下利 用个人自身条件的能力及意愿。核心素养里社会与公民素 养及文化意识都是从个人角度来出发及落实的。

核心素养的个人性表现为, 无论核心素养与个人特性 关联如何, 它一定是雇员个人潜在或者习得的某种能力的 外在体现。

\section{2. 4. 组织性}

核心素养的社会性决定了它的组织性。对于组织而言, 个人核心素养是其可利用的资源, 甚至是组织在竞争中不 可或缺的一部分。有能力的雇员能够使组织的竞争力更强, 这种优势是不可描述的。组织可以在雇员的核心素养基础 之上与雇员行成对话, 从而推动组织机构的完善。组织也 可以利用个人核心素养建立激励雇员的行为模型机制。

“社会与公民素养”及“主动意识与创业精神”将核心 素养置身于社会及人际的交往中, 个人的组织性得以体现。

\section{3. 中国核心素养的特征}

中国经济政治已经发展到一定水平, 中国学生在PISA 测试中的表现也令世界惊叹, 但反观大多数公民的素养却 没有达到相应水准。基于此背景之下的中国核心素养, 从 文化基础的夯实, 到个人自主发展的养成, 再到社会参与, 体现着由点及面、由静态到动态的发展过程。更倾向于一 种以人的发展为基础而带动社会发展的连动性发展态势。

\section{3. 1. 系统性}

除此之外, 文化基础里的人文底蕴和科学精神, 实质 上互为辩证关系---人文的积淀为科学的思辨准备条件, 科 学的批判为人文素养的形成厘清思路。这两者从思想的不 同层面来锤炼个人, 推动着个人的发展。而自主发展里的 “学会学习”及“健康生活”也是从个人存在的方向来加以 指引。一个强调技能, 一个强调态度, 二者互为补充, 相 互印证。社会参与中的责任担当及实践创新, 即是从责任 及实践两方面加以说明。社会、国家及国际的责任为个人 发展提供保障, 劳动、解决问题及运用技术为实践创新的 实现奠定基础。这紧紧相扣的各环节, 处处体现着核心素 养的系统性。 


\subsection{2. 人文性}

中国核心素养三部分中, 有两部分与个人发展息息相 关。例如, 文化基础里包含的“人文底蕴”强调个人文化的 积淀、情怀的培养及审美的形成, 而“科学精神”则强调个 人的理性思维及批判探索精神的探究。二者皆是从个人的 成长及修养出发, 体现素养内涵的人文性。不仅如此, 自 主发展里的“学会学习”也是从善学、反思等方面出发, 引 导个人思考及学习。从个人文化内在角度出发, 促进个人 发展, 体现核心素养的人文性。除此之外, 自主发展里的 “健康生活”, 也要求人珍爱生命、健全人格, 并进行自我 管理, 从而也从个人生存角度, 促进个人发展, 体现核心 素养人文性。

\subsection{3. 广泛性}

中国核心素养内容分为三方面, 六要素, 十八要点。 各个要点的分布很清晰, 辐射的范围很广。例如, 从第三 层表意来看, 仅“人文底蕴”这一要素, 就包含了人文积淀、 人文情怀及审美情趣三方面内容。除了基础的文化沉淀之 外, 还应该侧重自身的情怀内在, 及欣赏外在的审美的培 养, 可谓是细致入里。从第二层自主发展的方面来看, 其 实也包含个人内在文化和生存能力的发展, 即“人文底蕴” 及“健康生活”。

“科学精神”里的勇于探究与“实践创新”里的解决问 题, 其实在某种程度上来说也具有共通性, 都是指个人以 实践的形式来探索, 继而解决问题的过程。这样核心素养 广泛性得以交叉体现。

中英核心素养的内涵上既有相同点，又有不同点。英 国以工作为基础的核心素养内涵之社会性、实践性更强, 而中国以个人发展为基础的核心素养内涵系统性、人文性 更强。

\section{4. 英国核心素养对中国核心素养研究的启示}

中英核心素养的内涵各有特色, 各有倾向, 但英国核 心素养的理论研究在时限及数据上相较于我国有较大优 势。早在 21 世纪初, 英国便在国内开始了核心素养的培养 研究, 而我国这几年才开始聚焦学生核心素养培养研究。 在对比中英两国核心素养特征基础上, 学者可以从以下几 个方面着手研究我国核心素养发展之路。

\section{1. 确定目标, 厘清思路}

以工作为基础的核心素养培养有着明确的目标---更 好适应社会中的工作及人群。英国在向上海中小学数学教 育方面取得的成绩取经时也提到, 中国学生学习的目的性 明确---因为他们知道“知识可以改变命运”[4]。由于目标明 确, 核心素养在培养及评估时皆能采用一定的经验及方法。 例如, 核心素养的培养,一般认为有以下三种方式: 第一, 是以成功经理人为榜样建立模型并模仿; 第二, 是建立在 对未来机制的设想条目之上; 第三, 是基于如何辨别、测 量及发展的基础之上, 区分优秀与普通[14]。而英国督导 所采用的三项一级指导, 如学生成就、学校教育效能及学 校领导与管理的效能这三点及其下属的多个指标能够较
为权威的动态评估中小学学生的学习效能及核心素养养 成情况。结果科学, 可信度高[5]。

核心素养与课程结合过程中, 教育者应该厘清思路, 着重考虑个人核心素养与知识、情境、表现及其与基本技 能之间的关系[15]。首先, 应该确定核心素养与核心知识 并不等同, 知识的积累并不一定能带来素养的提升, 素养 的提升却可以带来知识的迁移。其次, 核心素养与情境之 间相互依存而生。情境为核心素养的成长及发展提供土壤, 核心素养为情境的层次划定提供依据。再次, 内在的核心 素养与外在的表现之间互为因果。核心素养是外在表现的 基础及源泉, 外在表现是核心素养的输出及体现。最后, 核心素养与基本技能之间也相互关联、互相影响。至少在 我国，核心素养的发展是基于基本技能及基本知识习得的 演变过程之上。随着时间、科技等相关因素的影响, 核心 素养与基本技能之间的区别可能会变得模糊, 甚至重合。

在接下来将核心素养融入教学的过程中, 教育者必需 将以上问题带入到教学中, 并时刻反思才能确保核心素养 的落实培养。

\section{2. 立足个人, 融入教学}

如果将核心素养的培养与个人的发展及社会的发展 相结合, 那么核心素养培养的成效会更显著。无论是英国 还是中国的核心素养都是针对人而设定, 只要是人, 是社 会中的人, 那么其与社会的结合便不能避免。而且, 核心 素养的提升只能通过立足个人得以实现。基于个人核心素 养的表现, 更能体现个人价值及内在。

核心素养不止于个人, 而更应该是面向社会、面向他 人。核心素养转而面向社会或他人的过程, 即是核心素养 与教学相结合的实践过程。虽然我国学者对核心素养培养 之路的争论声仍然没有停止[1], 但笔者认为, 无论是哪条 路, 课程内外的教育这一重要环节至关重要。对于核心素 养的培养不能仅仅只是停留在素养、能力、成效及技能等 方面, 而更应该是理解力、辨识力及申辩力等心智性内容 的培养[16]。教学的融入过程应是全方位、多角度的。也 只有这样, 才能保证核心素养在教学中的落实较为全面, 而且有行之有效。

\section{3. 多样评价, 祛除功利}

核心素养的目的是为了解决“培养什么样的人”这一 问题。那么它所面临的其实是人, 而人的知、情、意、行, 身、心、灵或心、手、脑有的可评估, 有的不可评估[16]。 如果评价的标准严苛, 则会将人工具化, 那么核心素养将 不是解决培养什么样的人, 而变成了生产什么样的机器。 在评价过程中, 应该注意评价的手段多样化、评价过程内 涵化、评价主体广泛化、评价指标数据化及评价内容简单 化。只有这样, 评价结果才能更加客观、公正。当然, 在 核心素养培养过程中让学生感觉“幸福”, 也是一项评价指 标。

除此之外, 核心素养培养过程中的功利性也应极力避 免。这也就要求, 我们的教育相应也该去功利性。只有真 正做到了“教育”，核心素养培养人的目的才能达成。 


\section{5. 结论}

国内对核心素养的研究还处于起步阶段, 对核心素养 的研究也还有很长一段路要走。本文对比中英文核心素养 内涵异同, 并将中英核心素养所强调的内容加以分析, 指 出中英两国在核心素养表述及特征上的不同。由于篇幅有 限, 本文只探讨了核心素养概念及意义设置方面的异同, 尚未详细讨论核心素养在课程实施及效果评估等方面的 异同。接下来的研究当中, 笔者将会慢慢将核心素养与课 程教学结合起来。希望能为高校师范生核心素养培养做一 些研究, 也为核心素养与课程的结合培养及评估等提供一 些参考。

\section{致谢}

本文为武汉市教育科学规划办一般项目《高职英语教 育专业人才核心素养培养研究》2016C241)的阶段性成果 之一。

\section{参考文献}

[1] 辛涛, 姜宇, 林崇德. 论学生发展核心素养的内涵特征及 框架定位 [J].中国教育学刊, 2016, 46(1): 35-46。

[2] 裴新宁, 刘新阳. 为 21 世纪重建教育---欧盟“核心素养”框 架的确立[J]. 全球教育展望, 2013, 42(12): 89-102。

[3] 张娜. DeSeCo项目关于核心素养的研究及启示[J]. 教育科 学研究, 2013(10): 39-45。

[4] 孙河川, 向琴群, 金荵. 如何评价学生的学习效能和核心 素养: 以英国督导测评点为例 [J]. 现代教育管理, 2016(4): 68-74。
[5] 陈法宝. PISA测评对英国基础教育改革动向的影响---例论 “中英数学教师交流项目”[J]. 基础教育, 2016, 13(5): 90, 107-112。

[6] 张紫屏. 基于核心素养的教学变革---源自英国的经验和启 示 $[J]$. 全球教育展望, 2016, 35(7): 4-13。

[7] 郭婧. 基于PISA测试结果的英国基础教育改革政策评析 [J]. 外国中小学教育, 2014(2): 6-10。

[8] 汪潮, 吴奋奋. 教学双基论的回顾和反思 [J]. 课程·教材·教 法, 1996(12): 5-9。

[9] 余文森. 从三维目标走向核心素养 $[\mathrm{J}]$. 华东师范大学学报 （教育科学版），2016(1): 11-13。

[10] 顾明远. 核心素养：课程改革的原动力 $[\mathrm{J}]$. 人民教育, 2015(13): 17-18。

[11] 程晓堂, 赵思奇. 英语学科核心素养的实质内涵 [J]. 课程·教 材·教法, 2016, 36(5): 79-86。

[12] Scottish Qualifications Authority. Policy and Research [Z]. 2003.http://www.sqa.org.uk/files_ccc/Key_Competencie s.pdf.

[13] 褚宏启. 学生发展核心素养六人谈--核心素养的概念与本 质[J]．华东师范大学学报(教育科学版), 2016(1)。

[14] Thomas N. Garavan \& David McGuire. Competencies and workplace learning: some reflections on the rhetoric and the reality [J]. Journal of Workplace Learning, 2001, 13(4): 144-163.

[15] 张华. 论核心素养的内涵 [J]. 全球教育展望, 2016(4): 10-24。

[16] 刘云杉. “核心素养”的局限: 兼论教育目标的古今之变 [J]. 全球教育展望, 2017, 46(1): 35-46。 